\title{
How to Provide for an Appropriate Dealing with Business Decision-Making from the Viewpoint of Informing

\author{
Vojko Potocan \\ University of Maribor, Slovenia
}

\author{
Vojko.potocan@uni-mb.si
}

\begin{abstract}
Economics of business decision-making (BDM) is target-oriented into management of the economic flow of business activities. Has a major impact on the level of quality of enterprise's operation. Business decision-making (BDM) is based on information, which shows the characteristics of the decisions and provides an additional and necessary knowledge. The main field of the management of the BDM is presented by the economic treatment of decisions, which are based on various information. The picture of the BDM is illustrated by various sorts, types and forms of information that are primarily created by the target-oriented information systems. These ensure a corresponding structured quality information for BDM at the selected levels of management. Due to the tradition, the usual business information hardly meets criteria of contemporary holism.
\end{abstract}

Keywords: "BDM", "Information starting points", "Information for BDM", "Economical information"

\section{The Selected Problem and Viewpoint of this Contribution}

Competitive pressure over the businesses, in the globalisation of the world economy, requires a high quality business operation. Business operation of enterprises can be significantly improved mainly in the field of its management, which is its least developed and investigated area (Potocan, 1997; Sauter, 1997; Fry, Stoner, 2000). The central phase of management is business decision-making (BDM), which, to a great extent, determine the quality of the entire management and has also a major impact on the results of business operation (Potocan, Kajzer, Mulej 1997).

In this contribution, the BDM is based upon the information platform /starting points with which we represent important characteristics of the examined field and the additional knowledge (from the content and methodological aspect) (Borghoff, Pareschi, 1998; Laudon, Laudon, 1998; Schultheis, Sumner, 1998).

Material published as part of this proceedings, either on-line or in print, is copyrighted by the author with permission granted to the publisher of Informing Science for this printing. Permission to make digital or paper copy of part or all of these works for personal or classroom use is granted without fee provided that the copies are not made or distributed for profit or commercial advantage AND that copies 1) bear this notice in full and 2) give the full citation on the first page. It is permissible to abstract these works so long as credit is given. To copy in all other cases or to republish or to post on a server or to redistribute to lists requires specific permission from the author.
The necessary information is formed in the processes of business operation and others' processes (partial or subprocesses) of supports of decision-making (Potocan 2000).

The development of the informative organization of the enterprise's operation enables the acquisition of both noneconomic and general economic information on the picture of business operation under evaluation.

The main field of the BDM presents the economics-oriented decision, which is based on various sorts and types of information (quantitative, qualitative). For the adequate implementation of the BDM we, namely, need an entirety of various information with which quantity, value and quality (or any other important) characteristics of BDM are presented. However, their treatment is linked to the variety of content and methodology issues (Jennings, Wattam, 1998; Gunton 1998).

The BDM can be considered as adequate when it takes place successfully (efficient and effective in economical terms), respected (from the aspect of business behaviour) and ethical (morally adequate from the aspect of a responsible attitude towards the social and natural environment). For this treatment, the BDM needs different kinds of information that can broadly be defined as general information (Potocan 1997; Potocan 2000). The majority of general information can also have a direct or indirect impact on the economics of BDM. For this reason, the information - connected with the BDM - can be also defined as economic information in the broadest sense of 


\section{BDM From the Viewpoint of Informing}

the word. In the BDM treatment, we can also encounter a group of information that can be defined as non-economic information (from the working aspect). These are the messages, data or information that are not related to the BDM or are not included (and or are not applied) in the treatment of BDM. The problem of the theory and practice of business informatics since its beginnies lies in the target orientation to ensure the direct economic information (Gunton, 1998; Lucey, 1998; Becker, Kugeler, Rosemann, 2000). In the past, information support was very often limited only to the financial aspect of the economics business operation. Financial information presents, nevertheless, an important group of information and is, at the same time, also only a part of a needed entire information support of business operation. The focus of modern business information is in providing of the entirety of information necessary for the business operation of economics. Herein, the increased importance of a group of information, which from the content aspect is not only economic, has however an important (indirect or direct) impact on the economic operation. Owing to its significance and impact on the economics of BDM, we have defined this information as (direct) economics information.

The treatment of indirect economic information is additionally made more difficult because of the problems linked to its definition (Potocan, Kajzer, Mulej 1997; Sauter 1997; Edwards 1997). At the level of its content definition, the information can be determined as objective and subjective. The objective infuriation is the information that can be well defined and, therefore, well investigated on the basis of different quantity units (i.e.: quantity, weight, value). On the other hand, we have subjective information that can not be sufficiently defined and this information is, as a rule, examined by the application of various quality units or even only by the application of descriptive criteria. However, we have not yet exhausted the problems how to define the objectivity and subjectivity of information, which can be treated further or through the needs and sufficient objectivity. The problem lies in non-implemented investigations that could thoroughly study the issues of the content subjective information and/or the subjectivity of the information definition.

A needed information structure for the BDM implementation presents an additional problem as concerns the treatment of the BDM information support (Potocan, Kajzer, Mulej, 1997). In this, we are encountered with the two aspects of the structure suitability, i.e.: and adequately target oriented information and a suitable level of generalization of information. For the needs of the individual BDM (different kind, type and form) and BDM in the individual areas of work, we need the information that is suitably conceived and created in accordance with the set goals of the work. On the other hand, we need a different general information for each BDM.

The information can be created by a different level of generalization based on the need and requirements of the BDM. Herein, the level of generalization can be in the interval between an entirely general information and a completely specific information. The discussion of all presented problems of the concept and the creation of the entirety of the BDM information support surpasses a possible and a definite scope of this contribution. From this reason, we shall only summarize selected cognition's, and present a processing concept of the treated economic information of the accountancy and elaborate them in compliance with the need of the entire as well as with the systemic treatment of the BDM information support.

In the continuation of this contribution we shall, therefore, focus on the presentation of the basic economic features of $\mathrm{BDM}$ and on the starting points of BDM in terms the general information and the economic information.

\section{The Starting Points of the Economic Examination of BDM - A Process Approach}

Due to the restricted availability of the economical sources necessary for the implementation of business processes and due to other restrictions (market, supply), the business system can not meet all possible management measures for the realization of all adequate economic results of business operation (Potocan 1997).

The understanding of the fundamental economical characteristics of business decisions requires the knowledge of (Goodwin, Wright, 1997; Porter, Norton 1997; Borghoff, Pareschi, 1998):

- The economic characteristics of a decision (use of the inputs, execution of processes, attainment of outputs);

- $\quad$ Suitability of the use of the availability of resources (inputs) for the execution of the process, and

- $\quad$ The impact of decisions on the business performance of the entire business operation.

Segments, phases and entirety of business decision requirements are studied from the selected view points of 
business decisions. The economical examination of the business operation system includes the investigation of all situations and changes of the economic categories that are linked to its implementation (forms of properties, obligations to the sources of property, business results). The most important economic categories of business operation can be presented by the business efficiency, cash and financial statement (Chystal, 1997; Davidson, 1998; Brewster, 1998), in the most condensed version and terms of outcome.

- The business performance statement is intended to monitor and to judge the business efficiency of the implementation of business processes. It is the basic statement of the economical operation, which includes the discussion of changes of the economical categories and their results. It is applied at the internal management of business operation.

- The cash statement is designed to follow and judge monetary efficiency of carrying out of the production processes on which the external factors of financing have the influence (incomes, expenditures).

- The financial statement is meant to follow and judge the process and the results of the financial elements of business operation of the unit of the account consideration in the selected period of examination.

- The elements of the individual statements are examined from the aspect of their positions in the chosen time - events (examination of the characteristics of their positions, joint results) and their dynamics - the flows in a definite period of time.

For the economical management of business operation the statement of the business performance flow is used including the presentation of the fundamental economical characteristics of business operation.

The process of the economic examination of business decisions includes the following phases (Potocan 2000).

- We begin the process by the definition of the starting points and the mode of the discussion of the business decision (selection of the statement, the scope of the accompanying, definition of the economical categories, units of measurements for the accompanying, the time period of examination).

- We continue by the determination of factors, which influence the process and the results of decision-making (characteristics of the field, applied methodologies, business process, business system, environment).

Direct economic examination covers the determination of the mode of examination, the definition of the decision characteristics, the formation of possible alternative decisions, the definition of alternatives, the analysis of the statement's components for the individual variants, the definition of the mode and criteria for the selection of the decision, the selection of the most appropriate decision and analysis of the impact of the envisaged result of the decision on the business performance.

The factors of the selected business performance flow are examined from the aspects of quantities, values, flows and movement (dynamics in the period of time).

\section{Informative Characteristics of the BDM - A Process Approach}

The process of the formation of the information starting points of the business decision-making takes place as follows (Potocan, Kajzer, Mulej 1997; Chrystal, 1997; Drury 1997):

We begin the formation of the information bases for the determination with the definition of the necessary quality (adequate programming, current, controlling, intervention), quantity (changeable quantity, sufficient volume), timewise suitability (punctuality, time-harmonization, frequency), suitability of macro and micro allocation of information. Later-on, on this basis, an adequate information technique and technology can be chosen.

This is followed by the definition of the additional knowledge on:

- The subject to decision-making situation (presentation of the characteristics of the business system and the environment in which it operates);

- The object of decision-making (presentation of the systemic knowledge for management), and

- The methodology and methods.

The information system supporting the business decisionmaking is located on the intersection of the information and management process. It is target-directed on the formation of information on events and on possible future development (of a company, and its selected environments). 


\section{BDM From the Viewpoint of Informing}

Herein, the information system supporting the BDM uses the information infrastructure including adequate bases of information (information sources in the enterprise and in the environment), the instruments for processing and presentation of information, and the information appliances for the exchange of messages. Its application makes possible the construction of flexible information systems for the individual levels and areas of business operation.

The entire information support to decision-making is provided by a synergetic operation of:

- The information systems for the implementation, which ensure a general information support, and

- The purpose-built information systems, which provide target-support to a part of the individual levels of management.

The individual levels of management need various information for a qualitative work (Potocan 1997). The created information presents the basic for the employees' decisionmaking and for the managers of processes, who carry out the operation-level management (formation of work instructions, execution, elaboration of reports on work). The more demanding decision-making of experts and managers carrying out the activities at the tactical level is based upon the purpose-formatted information. The work of the executives within the activities at the strategic level and policy is based on

\section{The Formation of the Economic Information for BDM}

The study of the economical characteristics of BDM is based on the data bases formed in the implementation of a business process and in the processes of the accounting support to BDM (Goodwin, Wright, 1997; Porter, Norton 1997; Brewster, 1998). The basic information support in the BDM is provided by the accounting system of following and studying the economical categories of business operation including bookkeeping, accounting planning, analyzing and controlling. Accounting presents the evaluated picture of business operation from the viewpoints of costs, financial and administration evaluated (Drury, 1997; Davidson 1998).

Cost accounting is an analytical accounting of the internal business operation. Herein, there are accounting and investigation of elements, costs and effects, business performance of the individual parts of the business process, and the operation of the organizational units (Goodwin, Wright, 1997; Chrystal 1997). General economical characteristics of the business process are illustrated by the data of cost accounting.

Financial accounting is a general accounting of the entire business operation. It deals with the accounting accompanying and examination of assets, obligations to the sources of resources, revenues and expenditure, inflows and outflows and income and expenses. It discusses, in more detail, business relation of a selected unit with other units and non-business relations within its framework (Drury, 1997; Fry, Stoner, 2000).

By the data of the financial accounting we present the characteristics of the evaluated flows of business operation (cash management, working capital, investments, fixed assets, shares and other securities). The financial data are used in the processes of the formation of the statements on financing (internal, external).

Management accounting presents a restructured part of the financial and cost accounting dealing with the formation of the accounting information necessary for the business operation management (Jennings, Wattam, 1998; Loudon, Loudon, 1998; Becker, Kugeler, Rosemann, 2000). The information is intended to be applied in the information system of management accounting (internal information for the work of managers) but it is not always formed in conformity with the accounting principles white the evaluations of their future evaluated are used for decisionmaking in the present time. It neither has a prescribed permanent volume and presentation form.

By the operation of the accounting system, we can create the business information on economic picture of business operations that, in synergy with other information, forms an entire information system supporting the decision-making. However, the decision-making in the individual areas and/or levels of management also demands specific economical information that is formed and structured to meet a target (Edwards, 1997; Lucey, 1998).

The economic information for decision-making at the executive level of management is provided by a restructured part of the management accounting, e.g. managerial accounting (Porter, Norton, 1997; Davidson, 1998). Through the purpose-built information meeting the decision-making goals, this assures the economic information for the implementation of decision-making processes.

In the managerial accounting we can, for the formation of the economic information, use various methods of 
evaluation (full evaluation - full accounting, narrowed evaluation - differential accounting and method based on the responsibility - responsibility accounting) (Goodwin, Wright, 1997; Davidson, 1998; Schultheis, Sumner, 1998).

The topic of the discussed systems of the managerial accounting information can be, with respect to the purpose and goals of decision-making, presented by various economic categories (costs, various results, assets, obligation to the sources of resources, results of the investment decisions - investments).

The entire information system of the managerial accounting includes the information of the individual accounting as (sub)systems or partial systems. Its synergy enables a successful implementation of the business decision-making (Potocan, 2000). The holistic system also includes information of other accounting (costs, financial, management), management and the environment (internal, external)

In the accounting of full evaluation the management accounting information is formed and structured according to the costs units. The selected costs units are burdened with direct costs and with a part of general costs. The management accounting information formed by a full evaluation is used in the processes of the product price formation, the formation of business operation statements, performance report, balance sheet, performance indicators, and planning of future costs.

The information on the previous product costs is used for the management and analysis of the operation of costs units while the information on the future costs is used for the planning activities.

In the accounting, which is based on the method of a narrowed evaluation, i.e. differential accounting, we form the management accounting information structured in compliance with goals of BDM. Differential management information is used to study business decisions in which differently possible orientations of the management actions can be illustrated as decision-making variants. The information of differential accounting is used in the preparation processes and decision-making.

In the responsibility accounting the management accounting information is formed and structured in compliance with the responsibility points. The responsibility accounting collects and forms the following economic information on the planned and actual inputs, the outputs, and the business performance of the point of responsibility.

The information formed in such a way is used for the analysis of the management implementation, for the motivation of managers and in the process of budgeting.

\section{Some Conclusions}

In the circumstances of restrict by available factors and present conditions of business operation, the results can be primarily improved by an adequate management. Various solutions are available to improve the quality of management while important improvement is provided by a suitable implementation of its central phase, i.e. the decision-making process.

The management in business systems is oriented to the economical of operation. Also, a corresponding economical orientation of business decision-making should be provided in the formation and application of the decision-making system. The decision-making process is based upon the informative starting points with which we represent important characteristics of the examined field and the additional knowledge (from the content and methodological aspect). The necessary information is formed in the processes of business operation and accounting support of decision-making.

The development of the information supporting of business activities enables the acquisition of the non-economic and general economic information on the evaluated picture of business operation.

However, for a successful implementation of the business decision-making additional and specifically structured economic information is needed. The information is formed in the target (sub)systems or partial systems of information designed for the work of the individual levels of business decision-making.

The process of solving the decision problems from the economical aspect is based on the information created in the management accounting. This involves the information (sub)systems or partial systems of the full accounting evaluation, of the differential accounting and of the responsibility accounting. Their synergy of operation enables to enhance the quality of management and efficient orientation of business operation. 


\section{BDM From the Viewpoint of Informing}

The basic problem of the formation and of the application of the examined information system is the necessary entirety of the knowledge of the decision-making situation, of the object of decision-making (content knowledge), of the methods (knowledge of methodology), which provide their adequacy.

\section{References}

Becker, J., Kugeler, M., Rosemann, N. (2000). Prozessmanagement. Heidelberg: Springer-Verlag.

Borghoff, U., Pareschi, R. (1998). Information Technology for Knowledge Management. Berlin: Springer.

Brewster, D. (1998). Business Economics: Decision - Making and the Firm. Harlow: Adison - Wesley.

Chrystal, Alec (1997). Economics for Business and Management. Oxford: Oxford University Press.

Davidson, S. (1998). Managerial Accounting: An Introduction to Concepts, Methods, and Uses. Chicago: The Dryden Press.

Drury, C. (1997). Management Accounting for Business Decisions. Boston: Thomson.

Edwards, J. (1997). Decision Making with Computers. London: Pitman Publishing.

Fry, R., Stoner, C. (2000). Business: An Integrative Approach. Boston: McGraw Hill.

Goodwin, P., Wright, G. (1997). Decision Analysis for Management Judgement. New York: Wiley and Sons.

Gunton, T. (1998). Infrastructure: Building a Framework for Corporate Information Handling. New York: Prentice Hall.

Jennings, D., Wattam, S. (1998). Decision Making: An Integrated Approach. London: Pitman Publishing.
Laudon, K., Laudon, J. (1998). Management Information Systems: A Contemporary Perspective. New York: McMillan Publishing.

Lucey, T. (1998). Management Information Systems. London: Letts Company.

Porter, G., Norton, C. (1997). Management Accounting: The Impact on Decision Makers. Forth Worth: Dryden Press.

Potocan, V. (1997). What Kind of MES is Needed for Innovative Entrepreneurial Decision Making. In: Proc. of IDMT '97, pp. 249 - 257. Wien: Osterrreichische Computer Gesellschaft.

Potocan, V., Kajzer, S., Mulej, M. (1997). The Standardization of the Methodological Basis of Business Decision-making as a Contribution to the Revival of the Systems Theory. In: Problems of excavating cybernetics and systems. Amsterdam: Systemica, n. 1 -6, p. 259 268.

Potocan, V. (2000): System of the standard decision-making processes. In: Allen Janet, Wilby Jennifer (ed.). Proceedings of the World congress of the systems science,. Toronto: ISS, 17 pages.

Sauter, V. (1997). Decision Support Systems: An Applied Managerial Approach. New York: Wiley and Sons.

Schultheis, R., Sumner, M. (1998). Management Information System. Boston: McGraw Hill.

\section{Biographies}

Dr. Vojko Potocan is an Assistant professor of management on Faculty of Economics and Business, where he teaches three courses: Business Processes, Operations Management, and Organization and Management. Dr. Potocan has authored 56 papers on the subject of Decision - making and Methodological basis of Business Decisions making. 